\title{
Communication
}

\section{Simultaneous Recognition of Dopamine and Uric Acid in the Presence of Ascorbic Acid via an Intercalated MXene/PPy Nanocomposite}

\author{
Qiannan You ${ }^{1,2}$, Zhongyang Guo ${ }^{1,2}$, Rui Zhang ${ }^{1,2}$, Zhimin Chang ${ }^{2}$, Mingfeng Ge ${ }^{2}$, Qian Mei ${ }^{2, *}$ \\ and Wenfei Dong $2, *$ (D)
}

\section{check for}

updates

Citation: You, Q.; Guo, Z.; Zhang, R.; Chang, Z.; Ge, M.; Mei, Q.; Dong, W. Simultaneous Recognition of Dopamine and Uric Acid in the Presence of Ascorbic Acid via an Intercalated MXene/PPy Nanocomposite. Sensors 2021, 21, 3069. https://doi.org/10.3390/ s21093069

Academic Editor: Scott Alan Trammell

Received: 1 February 2021

Accepted: 23 March 2021

Published: 28 April 2021

Publisher's Note: MDPI stays neutral with regard to jurisdictional claims in published maps and institutional affiliations.

Copyright: (c) 2021 by the authors. Licensee MDPI, Basel, Switzerland. This article is an open access article distributed under the terms and conditions of the Creative Commons Attribution (CC BY) license (https:// creativecommons.org/licenses/by/ $4.0 /)$.
1 School of Biomedical Engineering (Suzhou), Division of Life Sciences and Medicine, University of Science and Technology of China, Hefei 230026, China; youqn@sibet.ac.cn (Q.Y.); iszy.guo@foxmail.com (Z.G.); zhangrui@sibet.ac.cn (R.Z.)

2 Suzhou Institute of Biomedical Engineering and Technology, Chinese Academy of Sciences, Suzhou 215163, China; changzm@sibet.ac.cn (Z.C.); gemf@sibet.ac.cn (M.G.)

* Correspondence: qmei@sibet.ac.cn (Q.M.); wenfeidong@sibet.ac.cn (W.D.); Tel.: +86-512-6958-8307 (W.D.); Fax: +86-512-6958-8088 (W.D.)

Abstract: Two-dimensional (2D) MXenes have shown a great potential for chemical sensing due to their electric properties. In this work, a $\mathrm{Ti}_{3} \mathrm{C}_{2} \mathrm{~T}_{\mathrm{x}} /$ polypyrrole (MXene/PPy) nanocomposite has been synthesized and immobilized into a glassy carbon electrode to enable the simultaneous recognition of dopamine (DA) and uric acid (UA) under the interference of ascorbic acid (AA). The multilayer $\mathrm{Ti}_{3} \mathrm{C}_{2} \mathrm{~T}_{\mathrm{x}}$ MXene was prepared via the aqueous acid etching method and delaminated to a single layer nanosheet, benefiting the in-situ growth of PPy nanowires. The controllable preparation strategy and the compounding of PPy material remain great challenges for further practical application. A facile chemical oxidation method was proposed to regulate magnitude and density during the forming process of PPy nanowire, which promotes the conductivity and the electrochemical active site of this as-prepared nanomaterial. The MXene/PPy nanocomposite-modified electrode exhibited the selective determination of DA and UA in the presence of a high concentration of AA, as well as a wide linear range (DA: $12.5-125 \mu \mathrm{M}, \mathrm{UA}: 50-500 \mu \mathrm{M}$ ) and a low detection limit (DA: $0.37 \mu \mathrm{M}$, UA: $0.15 \mu \mathrm{M})$. More importantly, the simultaneous sensing for the co-existence of DA and UA was successfully achieved via the as-prepared sensor.

Keywords: simultaneous recognition; dopamine; uric acid; MXene/PPy nanocomposite

\section{Introduction}

Two-dimensional (2D) materials, which usually have an anisotropy of electrical characteristics, are promising candidates for use as electrode modified materials [1-3]. The 2D materials are restricted to two-dimensional planes due to their carrier migration and heat diffusion, making these materials exhibit many peculiar properties [4]. MXene, a new family of two-dimensional metal carbides, nitrides, and carbonitrides, has been a promising material in energy storage, membrane separation, electrochemical biosensors, etc. [5-7]. The formula of $M X e n e$ is $M_{n+1} X_{n} T_{x}$, wherein $M$ represents the early transition metal, $X$ is carbon and/or nitrogen, $T_{X}$ represents surface functional groups (including oxygen $(=\mathrm{O})$, hydroxyl $(-\mathrm{OH})$, or fluorine $(-\mathrm{F}))$, and $\mathrm{n}$ ranges from 1 to $3[8,9] . \mathrm{Ti}_{3} \mathrm{C}_{2} \mathrm{~T}_{\mathrm{x}}$ was generated by etching $\mathrm{Al}$ from an $\mathrm{Ti}_{3} \mathrm{AlC}_{2} \mathrm{MAX}$ precursor $[10,11]$, which exhibits unique electrical properties with a large surface area and is capable of using electrocatalyst analytes to construct chemical sensors [12-14]. Alongside this, the functional groups of $\mathrm{Ti}_{3} \mathrm{C}_{2} \mathrm{~T}_{\mathrm{x}}$ facilitate the subsequent chemical functionalization.

Polypyrrole (PPy) is a member of the conducting polymer family, which is arousing increasing attention owing to its high conductivity, good biocompatibility, and ease of synthesis $[15,16]$. Recently, conducting polymers and carbon-based nanomaterials have become 
promising candidates for use as electrode materials for electronic sensors. The performance of the conducting polymers being used directly as electrode materials can be optimized by a reasonable design of its synthesis and the regulation of its microstructure [17]. Compared with other conductive polymers, PPy possesses commercial application prospects in numerous applications, and can be used as a solid electrolytic capacitor, an anode material for secondary batteries, medical material, and an electrochemical sensor, among others [18-21]. The pyrrole monomer can be oxidized to polypyrrole via chemical oxidation or the electrochemical polymerization method [22,23]. However, the $\alpha$ and $\beta$ positions of the pyrrole monomer are easy to cross-link, since they possess similar polymerization capabilities during the polymerization process (such as forming granular polypyrroles) and result in the poor conductivity of PPy $[24,25]$. Hence, the controllable synthesis procedure for certain and regular micromorphology is essential to the sensing performance of electrochemical materials.

Dopamine (DA), a catecholamine neurotransmitter secreted by the human brain, is an extensive participant in the nervous system, coordinating the function of the pituitary gland to secret hormones [26,27]. Uric acid (UA) is the metabolite of purine in vivo, which is closely related to kidney stones, diabetes, coronary heart disease and hypertension, etc. [28]. Performing accurate trace recognition of DA and UA is of great importance for scientific research and disease prevention. Currently, traditional detection techniques, including High-Performance Liquid Chromatography (HPLC), phosphotungstic acid reduction, and ultraviolet spectrophotometry, are limited to in-situ and real-time detection applications due to their expensive cost and long detection period $[18,29,30]$. When compared to other detection technologies, electrochemical sensors have advantages in terms of their accurate, fast and online DA and UA monitoring capabilities. However, the oxidation potentials of DA and UA are adjacent to that of ascorbic acid (AA), which leads to an overlap on the ordinary electrode from these three organic molecules during the electrochemical detection process [31]. So far, the modified electrode nanomaterials (including polymers [32,33], carbon-based nanomaterials [33,34], noble metals, and other metal oxides [35,36]) have been applied to improve catalytic selectivity for small molecules. The decoration of polymers with carbon-based nanomaterials is a promising method to develop a new strategy towards the simultaneous sensing of DA and UA.

Herein, a novel chemical sensor based MXene/PPy nanocomposite was constructed via a simple chemical oxidation method. As shown in Figure 1 , the $\mathrm{Ti}_{3} \mathrm{C}_{2} \mathrm{~T}_{\mathrm{x}}$ nanosheets were delaminated using hydrofluoric acid to etch away the aluminum atoms. PPy nanowires with diameters of $\sim 200 \mathrm{~nm}$ were then composited into MXene single-layer nanosheets, which were regulated during the oxidation process. This as-prepared MXene/PPy nanocomposite material-modified electrode was applied towards the simultaneous sensing of DA and UA in the presence of AA. Due to the synergistic effects of conductive MXene and PPy with a well-defined nanowire structure, the nanocomposite modified electrode showed a wide detection linear range and a low detection limit. 


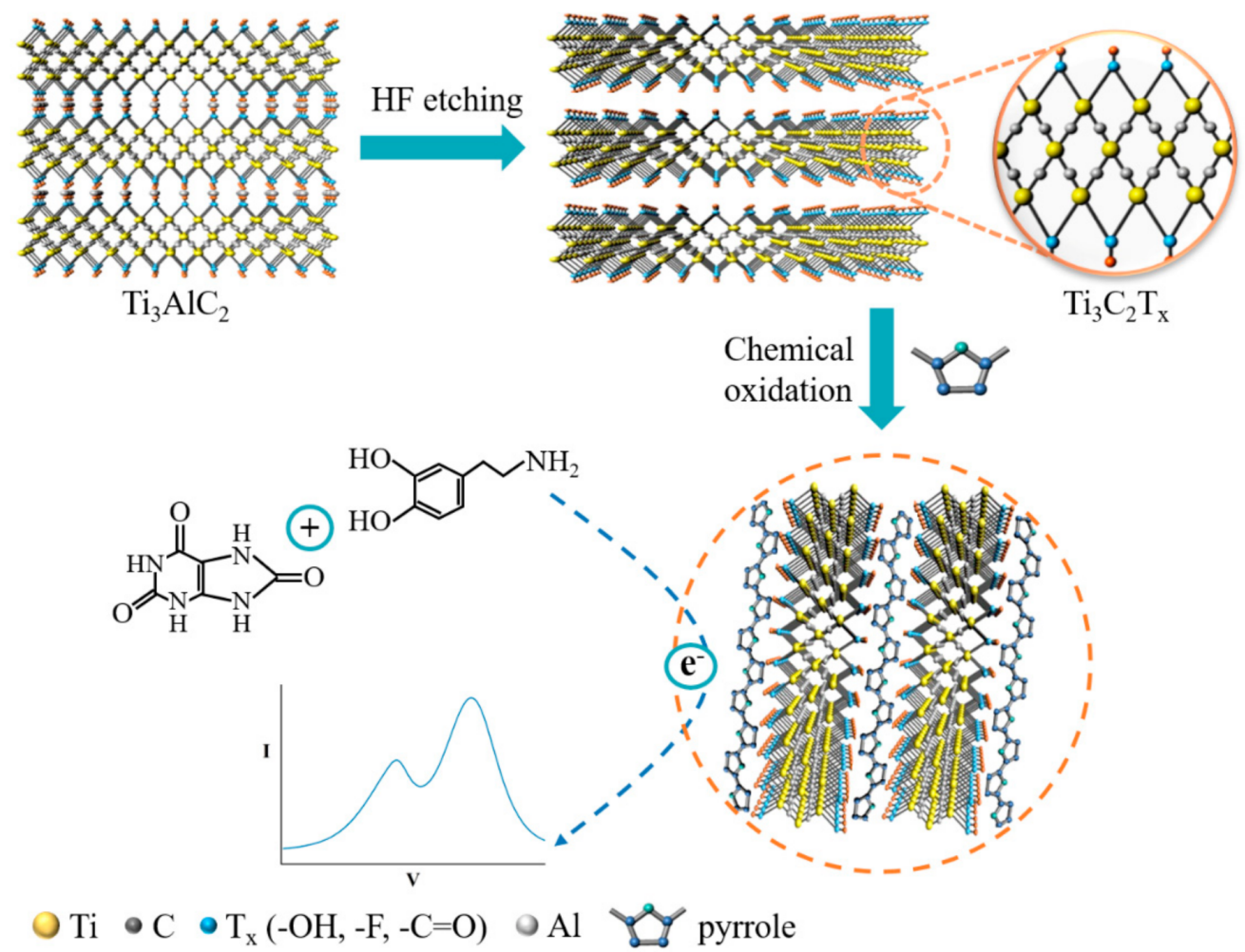

Figure 1. A schematic illustration of the synthesis of the MXene/PPy nanocomposite.

\section{Experimental}

2.1. Materials

Pyrrole $\left(\mathrm{C}_{4} \mathrm{H}_{4} \mathrm{NH}\right)$, Methyl orange $(\mathrm{MO})$ and Lithium fluoride $(\mathrm{LiF})$ were purchased from Shanghai Aladdin Biochemical Technology Co., Ltd., Shanghai, China. Iron (III) chloride $\left(\mathrm{FeCl}_{3}\right)$ was obtained from Sigma-Aldrich, Shanghai, China. Titanium aluminum carbide $\left(\mathrm{Ti}_{3} \mathrm{AlC}_{2}\right)$ powders were purchased from 11 technology Co., Ltd., Changchun, Jilin province, China, and Hydrochloric acid $(\mathrm{HCl})$ was obtained from Shanghai Lingfeng Chemical Reagent Co., Ltd., Shanghai, China. Dopamine (DA) and ascorbic acid (AA) were obtained from Shanghai Saan chemical technology Co., Ltd., Shanghai, China. Uric acid (UA) was purchased from Alfa Aesar Chemical Co., Ltd., Shanghai, China. All of the chemicals were directly applied without any further purification. The deionized water was applied for all solution preparations and washing steps.

\subsection{Synthesis of $\mathrm{Ti}_{3} \mathrm{C}_{2} \mathrm{~T}_{x}$ Powder}

The synthesis of $\mathrm{Ti}_{3} \mathrm{C}_{2} \mathrm{~T}_{\mathrm{x}}$ was based on the aqueous acid etching method. $0.666 \mathrm{~g} \mathrm{LiF}$ was added into $6 \mathrm{M} \mathrm{HCl}(10 \mathrm{~mL})$ and stirred at room temperature for $40 \mathrm{~min}$. Then, the $\mathrm{Ti}_{3} \mathrm{AlC}_{2}$ powders $(1 \mathrm{~g})$ were dispersed into the mixture solution to react at $35^{\circ} \mathrm{C}$ for $24 \mathrm{~h}$. The resulting suspension was washed alternately with ethanol and deionized water until the $\mathrm{pH}$ reached 6 , and was then dried overnight in a vacuum drying oven for a subsequent alternate preparation method.

\subsection{Synthesis of MXene/PPy Nanomaterial}

MXene/PPy was prepared through a chemical oxidation process. $\mathrm{Ti}_{3} \mathrm{C}_{2} \mathrm{~T}_{\mathrm{x}}$ powders were dispersed in deionized water and treated with powerful ultrasonication to delaminate them for use as nanosheets. Then, the $\mathrm{Ti}_{3} \mathrm{C}_{2} \mathrm{~T}_{\mathrm{x}}$ nanosheets were mixed into a solution of $0.1 \mathrm{M} \mathrm{FeCl}_{3}$ and $0.01 \mathrm{M} \mathrm{MO}$ and stirred for $30 \mathrm{~min}$ at room temperature. At last, $60 \mu \mathrm{L}$ pyrrole was added into the sample, followed by stirring at room temperature for $24 \mathrm{~h}$. The final MXene/PPy nanocomposite was created via centrifugation and vacuum drying in succession. 


\subsection{Preparation of the MXene/PPy Modified Electrode}

The synthesized MXene/PPy nanocomposite was dispersed in deionized water and stirred homogenously. Then, $10 \mu \mathrm{L}$ of the synthesized solution was dropped on the surface of the glassy carbon electrode (GCE, $\Phi=3 \mathrm{~mm}$ ) and the modified electrode was used as the working electrode.

\subsection{Characterizations and Electrochemical Measurements}

The morphology of the samples was characterized using a field emission scanning electron microscope (FESEM) (S4800, Hitachi, Japan). The sample structure and element analyses were performed using X-ray diffraction (XRD) (Cu-Ka line (0.15419 nm), D/MAX 2500 V / PC), Fourier transforms infrared (FT-IR) (Thermo Electron Corporation, Nicolet8700, USA), X-ray photoelectron spectroscopy (XPS, ESCLAB MKII), and transmission electron microscopy (TEM). UV-vis spectra were obtained using a UV-vis adsorption spectrophotometer (Agilent Cary 300 Scan). All of the electrochemical measurements were carried out using an electrochemical workstation (CHI 660E, Shanghai Chenhua Instrument Co., Ltd., Shanghai, China).

All electrochemical measurements were carried out in a three-electrode system. The as-prepared MXene/PPy nanocomposite was used as the working electrode. A Pt wire served as the counter electrode, and an $\mathrm{Ag} / \mathrm{AgCl}$ (saturated $\mathrm{KCl}$ ) electrode served as the reference electrode. The electrochemical properties of the working electrode were characterized by cyclic voltammetry (CV), electrochemical impedance spectroscopy (EIS) and differential pulse voltammetry (DPV).

\section{Results and Discussion}

\subsection{Characterization of MXene/PPy}

As illustrated by our design in Figure 1, the regular morphology of the PPy nanowire was controlled by the size of the $\mathrm{Ti}_{3} \mathrm{C}_{2} \mathrm{~T}_{\mathrm{x}} \mathrm{MXene}$ nanosheet during the oxidation process. The $\mathrm{Ti}_{3} \mathrm{C}_{2} \mathrm{~T}_{\mathrm{x}}$ MXene was first etched into a layered accordion-like structure, and the morphology of the precursor $\mathrm{Ti}_{3} \mathrm{AlC}_{2} \mathrm{MAX}$ powders and the delaminated $\mathrm{Ti}_{3} \mathrm{C}_{2} \mathrm{~T}_{\mathrm{X}}$ MXene were characterized in Figure $2 \mathrm{a}-\mathrm{c}$. The $\mathrm{Ti}_{3} \mathrm{C}_{2} \mathrm{~T}_{\mathrm{x}}$ exhibited a well-stacked multilayer structure after etching of the $\mathrm{Al}$ atom layers from the precursor $\mathrm{Ti}_{3} \mathrm{AlC}_{2}$ with $\mathrm{HF}$ treatment, as seen in Figure $2 \mathrm{~b}$. Then, the MXene nanosheets were easily produced by sonication. A certain amount of $\mathrm{Ti}_{3} \mathrm{C}_{2} \mathrm{~T}_{\mathrm{x}}$ powders was dispersed in deionized water followed by sonication to prepare a thin layer of MXene nanosheets. As shown in Figure 2c, the single-layer MXene nanosheets with a dimension of $\sim 1 \mu \mathrm{m}$ can be obtained after sonication and delamination for $45 \mathrm{~min}$. As for our synthesis in Figure 2d, large scale and homogeneous PPy nanowires were successfully prepared via the chemical oxidation method. The growth mechanism of the PPy nanowire was demonstrated in Figures S1 and S2, revealing the decisive function of the oxidant and demonstrating a template for the regulation of the nanostructure of PPy (Supplementary Materials). The nanostructure of the PPy nanowire was further examined using TEM, which possessed a uniform diameter of $\sim 200 \mathrm{~nm}$ under the optimal fabrication conditions (Figure 2e). With the addition of the $\mathrm{Ti}_{3} \mathrm{C}_{2} \mathrm{~T}_{\mathrm{x}}$ nanosheets, uniform nanowires were interspersed in stacked nanosheet layers (Figure 2f), showing the successful insertion of the PPy nanowires.

Figure 3a shows the XRD patterns of $\mathrm{Ti}_{3} \mathrm{AlC}_{2}-\mathrm{MAX}, \mathrm{Ti}_{3} \mathrm{C}_{2} \mathrm{~T}_{\mathrm{x}}-\mathrm{MXene}$, PPy, and MXene/PPy, respectively. When compared with their MAX precursors, the characteristic peaks located at $7.1^{\circ}, 14.4^{\circ}, 28.9^{\circ}$, and $36.1^{\circ}$ are assigned to the (002), (004), (006), and (202) facets of $\mathrm{Ti}_{3} \mathrm{C}_{2} \mathrm{~T}_{\mathrm{x}}$, respectively. This confirms that the $\mathrm{Ti}_{3} \mathrm{C}_{2} \mathrm{~T}_{\mathrm{x}}$ nanosheet was successfully converted after etching $\mathrm{Al}$ from the $\mathrm{Ti}_{3} \mathrm{AlC}_{2}$ powder. Alongside this, the typical PPy peak was observed at about $24^{\circ}$, which indicates an average chain of $\sim 4.38 \AA$ for PPy. When the PPy nanowire structures were formed on the $\mathrm{Ti}_{3} \mathrm{C}_{2} \mathrm{~T}_{\mathrm{x}}$ nanosheets, the diffraction pattern in Figure $3 \mathrm{a}$ indicated the well-defined lattice structure of this nanocomposite. Furthermore, FT-IR and XPS spectroscopy were applied to characterize the functional group of the MXene/PPy nanocomposite. The absorption peaks of $\mathrm{Ti}_{3} \mathrm{C}_{2} \mathrm{~T}_{\mathrm{x}}$ can be observed at $3357 \mathrm{~cm}^{-1}$ 
and $1645 \mathrm{~cm}^{-1}$, which correspond to $-\mathrm{OH}$ and $-\mathrm{C}=\mathrm{O}$, respectively (Figure $3 \mathrm{~b}$ ). The chemical composition of this nanocomposite before and after PPy oxidation was verified by the obtained XPS spectra. According to the characterization results in Figure $3 \mathrm{c}$ and Figure S3b, the PPy peak appeared under the existence of $\mathrm{Ti}_{3} \mathrm{C}_{2} \mathrm{~T}_{\mathrm{x}}$, and the other peaks were rarely changed. In the high resolution of the XPS spectrum for the Ti element in the MXene/PPy nanocomposite (Figure 3d), four peaks appeared at $454.3 \mathrm{eV}, 457.9 \mathrm{eV}, 460.7 \mathrm{eV}$, and $463.5 \mathrm{eV}$, which correspond to Ti-O, Ti (II), Ti-F, and Ti-O, respectively. The detailed combination of this nanocomposite was analyzed using the XPS results for $\mathrm{N} 1 \mathrm{~s}$ and $\mathrm{C} 1 \mathrm{~s}$. In Figure 3e, the binding energies of $397.6 \mathrm{eV}, 400.1 \mathrm{eV}$, and $402.7 \mathrm{eV}$ represented $-\mathrm{NH}-,-\mathrm{N}^{+} \mathrm{H}-$, and $=\mathrm{N}^{+}$-, respectively. Additionally, the $\mathrm{C}-\mathrm{N}$ located at $284.1 \mathrm{eV}$ from the $\mathrm{C} 1 \mathrm{~s}$ spectrum indicated the interactions between the pyrrole monomers and the MXene nanosheets (Figure $3 \mathrm{f}$ ). The above results demonstrated that the delaminated $\mathrm{Ti}_{3} \mathrm{C}_{2} \mathrm{~T}_{\mathrm{x}}$ nanosheets could maintain their crystalline structure during the oxidation of PPy.
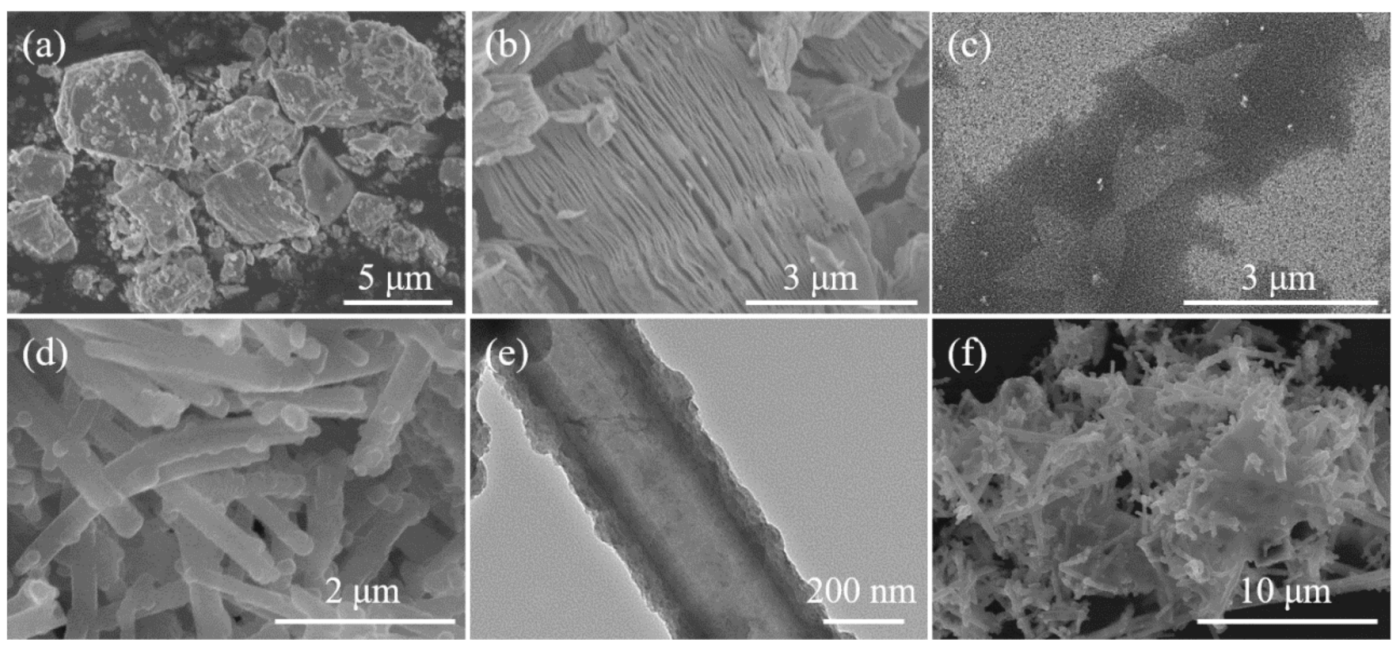

Figure 2. The synthesis of the MXene/PPy nanocomposite. A FESEM image of (a) $\mathrm{Ti}_{3} \mathrm{AlC}_{2}$ powders, $(\mathbf{b}) \mathrm{Ti}_{3} \mathrm{C}_{2} \mathrm{~T}_{\mathrm{x}}$ powders, (c) $\mathrm{Ti}_{3} \mathrm{C}_{2} \mathrm{~T}_{\mathrm{x}}$ nanosheets, and (d) PPy nanowires; (e) a TEM image of the PPy nanowire; (f) a FESEM image of the MXene/PPy nanocomposite.
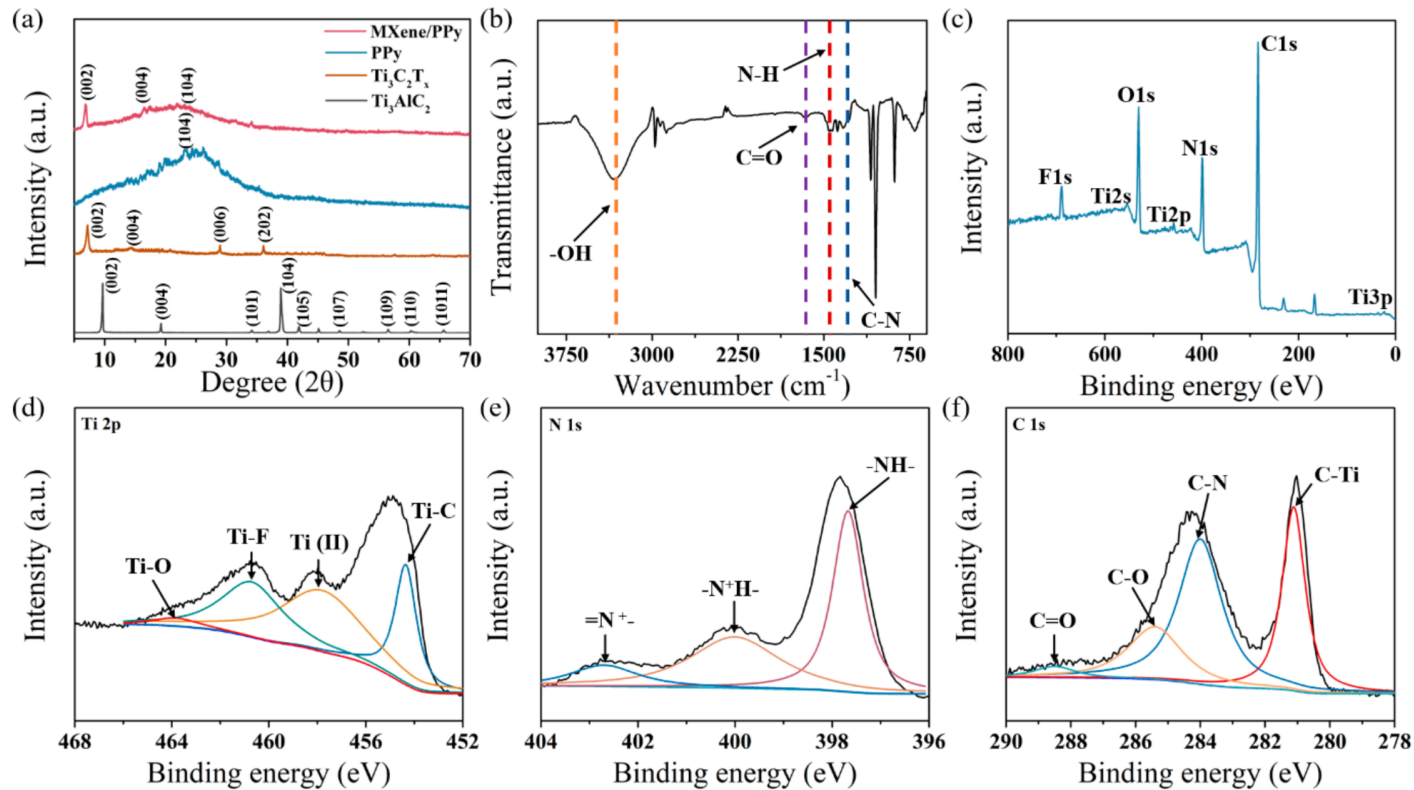

Figure 3. (a) The XRD patterns of $\mathrm{Ti}_{3} \mathrm{AlC}_{2}-\mathrm{MAX}, \mathrm{Ti}_{3} \mathrm{C}_{2} \mathrm{~T}_{\mathrm{x}}-\mathrm{MX}$ ene, PPy and MXene/PPy powders; (b) the FT-IR diagram of MXene/PPy powder; (c-f) the XPS spectra of MXene/PPy, Ti 2p, N 1s, and C 1s in the MXene/PPy nanocomposite, respectively. 


\subsection{Electrochemical Behaviors of MXene/PPy Modified Electrode}

The electrochemical behaviors of the MXene/PPy nanocomposite were investigated in Figure S4a. A cyclic voltammetry (CV) test was applied to characterize the electrochemical conductivity of the bare glassy carbon electrode (GCE), the pure PPy modified electrodes, and the MXene/PPy modified electrodes in 0.05 M PBS (Figure S4a). Compared with the pure PPy modified electrode, the MXene/PPy modified electrode showed two pairs of redox peaks (oxidation peaks at $0.21 \mathrm{~V}$ and $-0.48 \mathrm{~V}$, reduction peaks at $-0.17 \mathrm{~V}$ and $0.31 \mathrm{~V}$ ), which correspond to the electrocatalytic processes of MXene and PPy, respectively. It is obvious that the peak current exhibited a remarkable increase during both oxidation and reduction, indicated by the significant enhancement of the electron transfer rate via the introduction of the MXene nanosheet. EIS was used to evaluate the electron transfer resistance $\left(R_{\mathrm{ct}}\right)$ of the as-prepared electrodes in Figure $4 \mathrm{a}$. The Rct values of the bare GCE, the pure PPy modified electrodes, and the MXene/PPy modified GCE electrodes were calculated to be $109.63 \Omega, 23.09 \Omega$, and $15.34 \Omega$, respectively. The above results demonstrate that the participation of MXene enables the improvement conductivity of the PPy. The effective surface area of these modified electrodes was further investigated through CV with different scan rates ranging from 50 to $300 \mathrm{mV} / \mathrm{s}$ (Figure 4b). As shown in Figure 4c, the linear curves that present the relationship between the oxidation peak current, the square root of the scan rate, and the effective surface area can be calculated in accordance with the Randles-Sevcik equation [37-39]:

$$
\frac{\mathrm{I}_{\mathrm{p}}}{\mathrm{v}^{1 / 2}}=\left(2.69 \times 10^{5}\right) \mathrm{n}^{3 / 2} \mathrm{D}_{0}^{1 / 2} \mathrm{C}_{0}^{*} \mathrm{~A}
$$
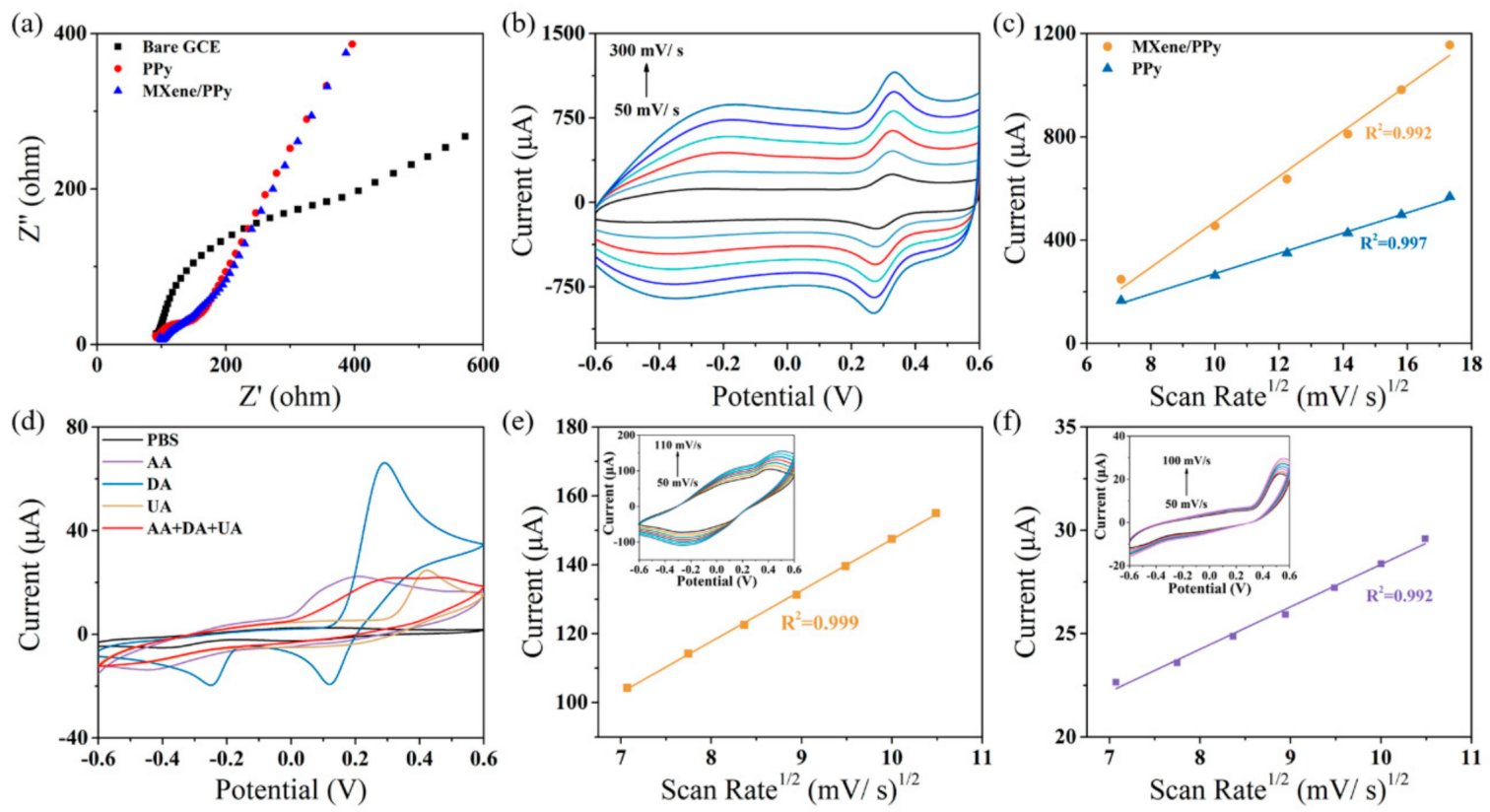

Figure 4. (a) Nyquist plots of bare, PPy modified, and MXene/PPy modified electrodes in the presence of $10 \mathrm{mM}$ $\left(\mathrm{Fe}(\mathrm{CN})_{6}\right)^{3-/ 4-}$ containing $0.1 \mathrm{M} \mathrm{KCl} ;(\mathbf{b})$ the $\mathrm{CV}$ curves of the MXene/PPy modified electrode with different scan rates (50, $100,150,200,250$, and $300 \mathrm{mV} / \mathrm{s})$ in $10 \mathrm{mM} \mathrm{K}_{3}\left(\mathrm{Fe}(\mathrm{CN})_{6}\right)$ containing $3 \mathrm{M} \mathrm{KCl}$; (c) the calibration curves of current peak vs. the square root of the scan rate for PPy modified and MXene/PPy modified electrodes; (d) the CV responses of the MXene/PPy modified electrode for $1 \mathrm{mM}$ AA, $50 \mu \mathrm{M}$ DA, and $100 \mu \mathrm{M}$ UA in $0.05 \mathrm{M}$ PBS; (e,f) the calibration curves of the current peak vs. the square root of the scan rate for the MXene/PPy modified electrode in $0.05 \mathrm{M}$ PBS containing $50 \mu \mathrm{M}$ DA and $100 \mu \mathrm{M}$ UA, respectively (the insert shows the CV curves of the MXene/PPy modified electrode with different scan rates $(50,60,70,80,90,100$, and $110 \mathrm{mV} / \mathrm{s}))$.

In this formula, $A$ is the specific surface area and $I_{p}$ and $v^{1 / 2}$ represent the peak current and square root of the scan rate, respectively. $\mathrm{C}_{0}^{*}$ is the concentration of the 
detection molecule, $\mathrm{n}$ is the number of electrons transferred in this redox process, and $\mathrm{D}_{0}$ is the molecular diffusion coefficient. A proportional relationship between $\mathrm{I}_{\mathrm{p}} / \mathrm{v}^{1 / 2}$ and $\mathrm{A}$ is the calculated basis of the effective surface area, in addition to the constant values $\left(\mathrm{n}, \mathrm{D}_{0}\right.$ and $\left.\mathrm{C}_{0}\right)$. The peak currents and the square roots of the scan rates exhibited a linear relationship, and the $\mathrm{I}_{\mathrm{p}} / \mathrm{v}^{1 / 2}$ is a fixed value that represents the Randles' slope. According to the calibration curves in Figure $4 \mathrm{c}$ and Figure S4b, the Randles' slopes of MXene/PPy and the pure PPy modified electrodes were calculated to be $88.11 \pm 4.05$ and $39.39 \pm 1.12$, respectively (Table 1). Therefore, it could be inferred that the effective surface area of the MXene/PPy $\left(2.87 \pm 0.13 \mathrm{~cm}^{2}\right)$ was increased to about 2.24 times that of the pure PPy $\left(1.28 \pm 0.04 \mathrm{~cm}^{2}\right)$ and is thus able to provide more electrocatalytic sites for sensing (Table S1).

Table 1. Performance comparisons of various modified electrodes for the simultaneous determination of DA and UA.

\begin{tabular}{cccccc}
\hline \multirow{2}{*}{ Electrode Materials } & \multicolumn{2}{c}{$\begin{array}{c}\text { Linear Range } \\
(\mu \mathbf{M})\end{array}$} & \multicolumn{2}{c}{$\begin{array}{c}\text { Detection Limit } \\
(\mu \mathbf{M})\end{array}$} & Reference \\
\cline { 2 - 5 } & DA & UA & DA & UA & \\
\hline PGE & $0.15-15$ & $0.3-150$ & 0.033 & 0.12 & {$[27]$} \\
Graphene flowers/CFE & $0.7-45.21$ & $3.78-183.87$ & 0.5 & 2 & {$[40]$} \\
Hema/GCE & $5-20$ & $2.5-20$ & 0.5 & 0.63 & {$[41]$} \\
CuZEA/RGO/ & $0.1-19$ & $20-200$ & 0.041 & 11 & {$[42]$} \\
$\begin{array}{c}\text { GCE } \\
\text { Mesoporous carbon }\end{array}$ & & & & \\
$\begin{array}{c}\text { nanofiber-modified pyrolytic } \\
\text { graphite electrode }\end{array}$ & $0.05-30$ & $0.5-120$ & 0.02 & 0.2 & {$[43]$} \\
$\begin{array}{c}\text { Poly (DBF) } \\
\text { Reduced graphene oxide/GCE }\end{array}$ & $0.2-200$ & $1.0-250$ & 0.2 & 0.03 & {$[44]$} \\
MXene/PPy & $12.5-125$ & $0.5-60$ & 0.5 & 0.5 & {$[29]$} \\
Current \\
\end{tabular}

$\mathrm{CV}$ measurement was further utilized to determine the optimal working potential of the MXene/PPy modified electrode for DA and UA sensing. The response results of the as-prepared electrode toward DA, UA, and AA were shown in Figure 4d. It is clear that the electrocatalytic reaction of these analytes can effectively separate the overlapped oxidation peak. For DA, an oxidation peak appeared at $0.29 \mathrm{mV}$, indicating the electrocatalytic effect of DA on o-dopaminoquinone at a MXene/PPy nanocomposite modified electrode. In the case of UA, the oxidation current peak increased at $0.42 \mathrm{mV}$ with the injection of $100 \mu \mathrm{M}$ $\mathrm{UA}$, implying that the reversible reaction of UA to diamine is intermediate. However, the injection of AA also altered the redox behavior of the as-prepared electrode, which indicates that the modification was responsive to the individual AA molecule. According to the above characterization results, the $\mathrm{CV}$ method was applied to allow for the separate recognition of DA, UA, and AA. The result in Figure 4d indicates that the MXene/PPy modified electrode can recognize DA and UA in the presence of AA and that the oxidation potential of both DA and UA show a slight offset towards positive potential. In addition, there is no obvious oxidant peak in AA with the simultaneous addition of DA, UA, and AA. Therefore, the as-prepared MXene/PPy modified nanocomposite can only respond to DA and UA in the presence of AA. Then, the sensing mechanisms of DA and UA on the as-prepared electrode surface were investigated using CV scans from $50 \mathrm{mV} / \mathrm{s}$ to $110 \mathrm{mV} / \mathrm{s}$ in $0.05 \mathrm{M}$ PBS (Figure 4e,f). The cyclic voltammetry results were fitted as shown in the insert; the oxidation peak currents of both DA and UA demonstrated a linear relationship with the square root of the scan rate. The simulation results present the finding that the catalytic oxidation processes of DA and UA are controlled via the diffusion process, and the as-prepared sensor is able to quantitatively determine DA and UA. 


\subsection{Sensing Performance of MXene/PPy Modified Electrode}

As designed, the composite of $\mathrm{Ti}_{3} \mathrm{C}_{2} \mathrm{~T}_{\mathrm{x}}$ and polypyrrole provides a substantial basis for the simultaneous determination of DA and UA in the presence of AA. To ensure the optimal potential of the DA and UA sensing process, the DPV method was applied to characterize the response current of the MXene/PPy-based sensor with the successive injection of variation concentration substances. Figure 5 shows two independent potentials at $0.23 \mathrm{mV}$ and $0.40 \mathrm{mV}$, which correspond to the oxidation of DA and UA, respectively. As observed in Figure $5 \mathrm{a}$, the peak current was increased after each addition of DA until the concentration of DA reached $125 \mu \mathrm{M}$ in $0.05 \mathrm{M}$ PBS containing $1 \mathrm{mM}$ AA and $100 \mu \mathrm{M}$ UA. Apparently, the initial injection of UA aroused an obvious peak, while AA hardly responded. In addition, the same phenomenon (Figure $5 \mathrm{c}$ ) can be observed with the concentration change of UA in the presence of $1 \mathrm{mM}$ AA and $50 \mu \mathrm{M}$ DA. As discussed above, the as-prepared sensor can independently sense DA and UA given the coexistence of AA, and resist mutual interference. According to the data in Figure $5 \mathrm{a}, \mathrm{c}$, the calibration lines of the peak current with the corresponding reactant concentration were simulated in Figure $5 b$, d, respectively. As shown in Figure $5 b$, the fitting linear equations of DA are $I_{D A}=9.928 C_{D A}+9.99$ $\left(R^{2}=0.998,12.5-50 \mu \mathrm{M}\right)$ and $I_{D A}=5.977 C_{D A}+12.061\left(R^{2}=0.995,50-125 \mu M\right)$, respectively $(I$ and $C$ represent the current intensity $(\mu \mathrm{A})$ and substrate concentration $(\mathrm{mM})$, respectively). Similarly, the linear calibration equation of $\mathrm{UA}$ can be fitted as $\mathrm{I}_{\mathrm{UA}}=99.008 \mathrm{C}_{\mathrm{UA}}+3.242$ $\left(\mathrm{R}^{2}=0.995,50-250 \mu \mathrm{M}\right)$ and $\mathrm{I}_{\mathrm{UA}}=50.16 \mathrm{C}_{\mathrm{UA}}+15.313\left(\mathrm{R}^{2}=0.990,250-500 \mu \mathrm{M}\right)$, respectively. These results demonstrate that the as-prepared sensor can separately examine DA and UA with a wide linear range and high sensitivity.

(a)
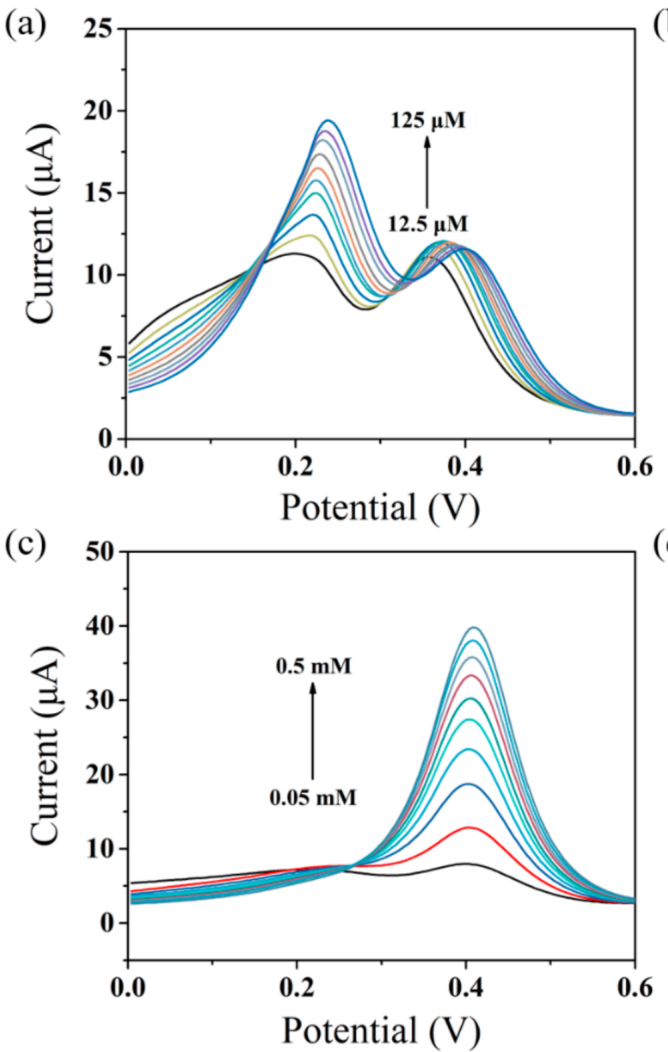

(b)

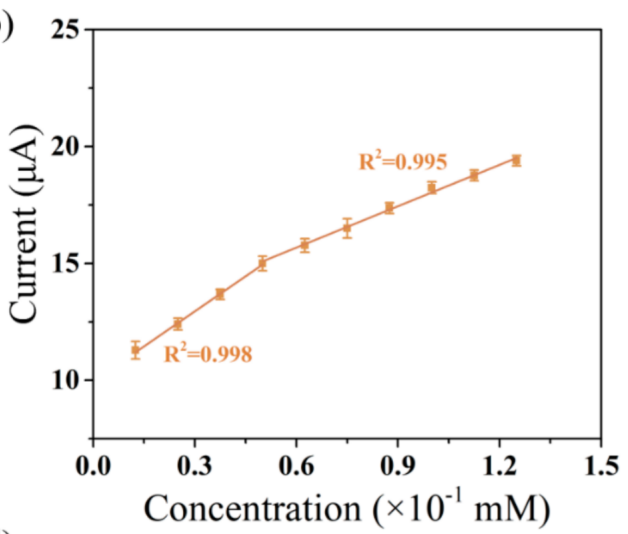

(d)

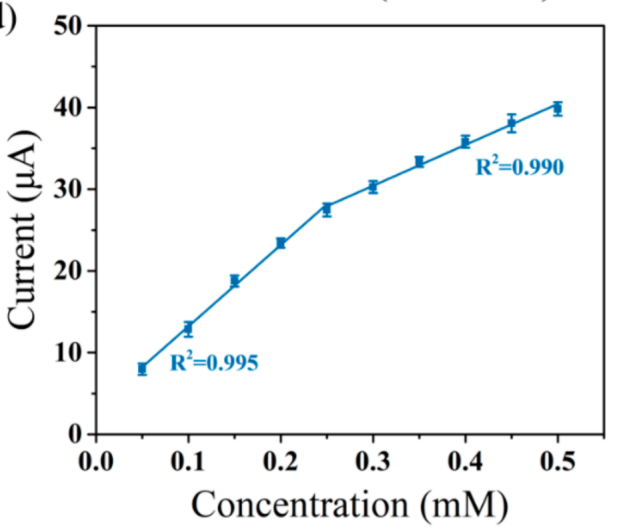

Figure 5. (a) Differential pulse voltammetry (DPV) responses of the MXene/PPy modified electrode with different DA concentrations in the presence of $1 \mathrm{mM}$ AA and $100 \mu \mathrm{M} \mathrm{UA}$; (b) a linear calibration curve for the current response of DA; (c) DPV responses of the MXene/PPy modified electrode with different UA concentrations in the presence of $1 \mathrm{mM} \mathrm{AA}$ and $50 \mu \mathrm{M} \mathrm{DA}$; (d) a linear calibration curve for the current response of UA. 
The synchronous sensing of DA and UA in the presence of AA was examined via the simultaneous injection of the two substances containing $1 \mathrm{mM}$ AA on the MXene/PPy nanocomposite modified electrode. As shown in Figure 6a, the oxidation peaks of DA and UA were relatively independent, and the addition of AA had a hard time interfering with the current signal. The linear calibration curves of DA and UA were also fitted between the current signal and the substance concentration in Figure $6 \mathrm{~b}$ (DA: 12.5-125 $\mu \mathrm{M}$; UA: $50-500 \mu \mathrm{M})$. In addition, the detection limits of DA and UA can reach $0.37 \mu \mathrm{M}$ and $0.15 \mu \mathrm{M}$, respectively (at an $\mathrm{S} / \mathrm{N}$ of 3). Obviously, there were rare sensing performance differences between the separate and simultaneous detection of the two molecules. For evaluating the performance of the as-prepared sensor, electrochemical stability is an essential index, obtained through CV measurement. Examining a comparison of the first- and twentiethtimes scan rates in Figure 6c, the tiny changes in the magnitude of the redox peaks indicate the excellent electrochemical stability of the MXene/PPy modified electrode for reactant sensing. Subsequently, the reproducibility of the as-constructed sensor was performed using nine MXene/PPy modified electrodes under the same conditions. The response signals were measured separately for the same addition of $50 \mu \mathrm{M}$ DA and $100 \mu \mathrm{M}$ UA. The relative standard deviations (RSD) of DA and UA in Figure 6d were calculated as $3.91 \%$ and $4.29 \%$, respectively, revealing the excellent reproducibility of the sensor-based MXene/PPy nanocomposite.

(a)

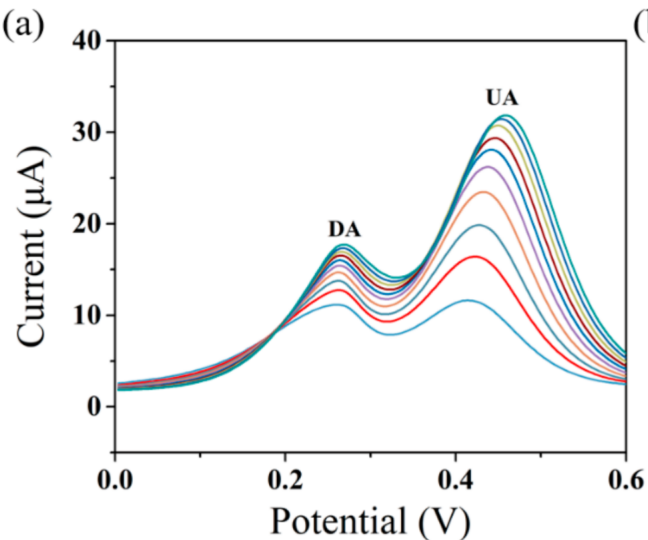

(c)

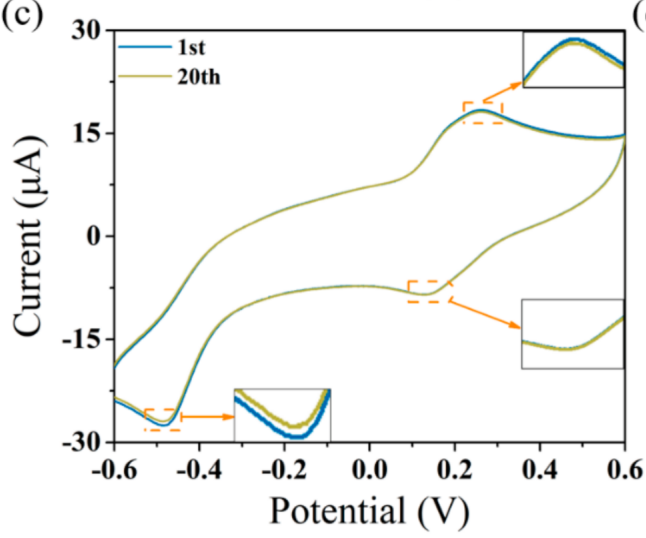

(b)

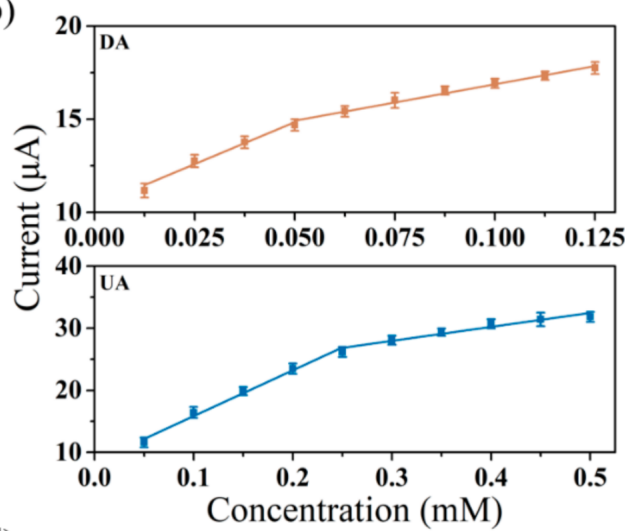

(d)

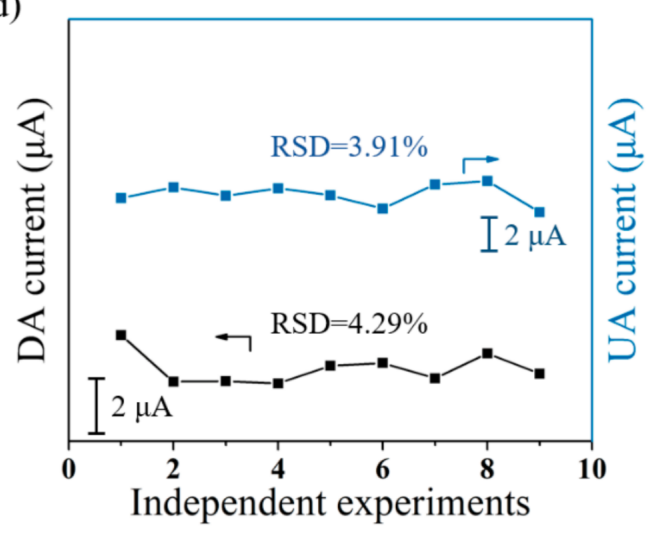

Figure 6. (a) DPV responses of the MXene/PPy modified electrode for the mixture containing DA $(12.5-125 \mu \mathrm{M})$, UA $(50-500 \mu \mathrm{M})$, and $1 \mathrm{mM} \mathrm{AA} ;(\mathbf{b})$ the linear calibration curves for the current response of DA and UA; (c) the stability of the as-prepared sensor after scanning in $0.05 \mathrm{M}$ PBS for 20 cycles; (d) the reproducibility of the as-prepared sensor in $0.05 \mathrm{M} \mathrm{PBS}$ containing $50 \mu \mathrm{M}$ DA and $100 \mu \mathrm{M} \mathrm{UA}$.

The sensing performance of the MXene/PPy modified electrode was compared with those of other reported sensors in Table 1. According to the data from Table 1, the sensorbased MXene/PPy material exhibited a wider linear range and a lower detection limit than 
did most other reported sensors. Furthermore, the low detection limit of the as-prepared sensor also promises a great potential for practical applications.

\section{Conclusions}

In this work, we synthesized delaminated $\mathrm{Ti}_{3} \mathrm{C}_{2} \mathrm{~T}_{\mathrm{x}}$ through the aqueous acid etching method and in-situ complexed PPy nanowire successfully via chemical oxidation. The regular structure of PPy nanowires was effectively controlled via the intercalation in the nanosheets of $\mathrm{Ti}_{3} \mathrm{C}_{2} \mathrm{~T}_{\mathrm{x}}-\mathrm{MX}$ ene. Under the optimized synthesis conditions, the composite material provides more active electrochemical sites owing to its larger effective surface area compared to pure PPy nanowire material. Meanwhile, the nanowire structure of PPy and the two-dimensional structure of $\mathrm{Ti}_{3} \mathrm{C}_{2} \mathrm{~T}_{\mathrm{x}}$ are conducive to the loading of target substances and the transfer of electrons. With a combination of these two promising materials, the as-prepared sensor exhibited a wide linear range and a low detection limit for the simultaneous sensing of DA and UA in the presence of AA and showed excellent stability and reproducibility. This work provides a new avenue for DA and UA recognition using two-dimensional materials and conductive polymer composite materials, and the designed electrochemical sensor has great potential in actual system monitoring.

Supplementary Materials: The following are available online at https://www.mdpi.com/article/ 10.3390/s21093069/s1. Figure S1: FESEM images of PPy with different concentration of oxidant, Figure S2: FESEM images of PPy with different concentration of MO, Figure S3: XPS spectra and UV-vis spectra, Figure S4: CV behaviors of bare, PPy and MXene/PPy modified electrode, Figure S5: Anti-interference and stability of MXene/PPy modified electrode, Table S1: Comparison of the electrochemical effective surface area of PPy modified and MXene/PPy modified electrode.

Author Contributions: Conceptualization, Q.Y.; methodology, Q.Y.; formal analysis, investigation, Q.Y., Z.G., R.Z., Z.C. and M.G.; writing—review and editing, supervision, Q.Y., Q.M. and W.D.; project administration and funding acquisition, Q.M. and W.D. All authors have read and agreed to the published version of the manuscript.

Funding: This work was supported by the National Key R\&D Program of China (Grand No. 2020YFC2004500), the National Natural Science Foundation of China (Grand No. 81771982, 61535010, 8160071152, 21803075, and 81902166), the Natural Science Foundation of Jiangsu Province (BK20181236 and BK20170389), the Primary Research \& Development Plan of Jiangsu Province (BE2019683), and the Science and Technology Department of Jinan City (2018GXRC016).

Institutional Review Board Statement: Not applicable.

Informed Consent Statement: Not applicable.

Data Availability Statement: Not applicable.

Conflicts of Interest: The authors declare no conflict of interest.

\section{References}

1. Dral, A.P.; ten Elshof, J.E. 2D metal oxide nanoflakes for sensing applications: Review and perspective. Sens. Actuators B Chem. 2018, 272, 369-392. [CrossRef]

2. Liu, H.; Duan, C.; Yang, C.; Shen, W.; Wang, F.; Zhu, Z. A novel nitrite biosensor based on the direct electrochemistry of hemoglobin immobilized on MXene-Ti ${ }_{3} \mathrm{C}_{2}$. Sens. Actuators B Chem. 2015, 218, 60-66. [CrossRef]

3. Hantanasirisakul, K.; Gogotsi, Y. Electronic and Optical Properties of 2D Transition Metal Carbides and Nitrides (MXenes). Adv. Mater. 2018, 30, 1804779. [CrossRef]

4. Shen, J.; Liu, G.; Ji, Y.; Liu, Q.; Cheng, L.; Guan, K.; Zhang, M.; Liu, G.; Xiong, J.; Yang, J.; et al. 2D MXene Nanofilms with Tunable Gas Transport Channels. Adv. Funct. Mater. 2018, 28, 1801511. [CrossRef]

5. Chen, Y.; Xie, X.; Xin, X.; Tang, Z.R.; Xu, Y.J. Ti ${ }_{3} \mathrm{C}_{2} \mathrm{~T}$ x-Based Three-Dimensional Hydrogel by a Graphene Oxide-Assisted Self-Convergence Process for Enhanced Photoredox Catalysis. ACS Nano 2019, 13, 295-304. [CrossRef]

6. Zhang, Y.; Jiang, X.; Zhang, J.; Zhang, H.; Li, Y. Simultaneous voltammetric determination of acetaminophen and isoniazid using MXene modified screen-printed electrode. Biosens. Bioelectron. 2019, 130, 315-321. [CrossRef]

7. Yang, C.; Xu, D.; Peng, W.; Li, Y.; Zhang, G.; Zhang, F.; Fan, X. Ti ${ }_{2} \mathrm{C}_{3} \mathrm{Tx}$ nanosheets as photothermal agents for near-infrared responsive hydrogels. Nanoscale 2018, 10, 15387-15392. [CrossRef] 
8. Ng, V.M.H.; Huang, H.; Zhou, K.; Lee, P.S.; Que, W.; Xu, J.Z.; Kong, L.B. Recent progress in layered transition metal carbides and/or nitrides (MXenes) and their composites: Synthesis and applications. J. Mater. Chem. A 2017, 5, 3039-3068.

9. Liu, G.; Shen, J.; Liu, Q.; Liu, G.; Xiong, J.; Yang, J.; Jin, W. Ultrathin two-dimensional MXene membrane for pervaporation desalination. J. Membr. Sci. 2018, 548, 548-558. [CrossRef]

10. Weng, C.; Xing, T.; Jin, H.; Wang, G.; Dai, Z.; Pei, Y.; Liu, L.; Zhang, Z. Mechanically robust ANF/MXene composite films with tunable electromagnetic interference shielding performance. Compos. Part A Appl. Sci. Manuf. 2020, 135, 105927. [CrossRef]

11. Zeng, Z.; Wang, C.; Siqueira, G.; Han, D.; Huch, A.; Abdolhosseinzadeh, S.; Heier, J.; Nuesch, F.; Zhang, C.J.; Nystrom, G. Nanocellulose-MXene Biomimetic Aerogels with Orientation-Tunable Electromagnetic Interference Shielding Performance. Adv. Sci. 2020, 7, 2000979. [CrossRef]

12. Li, M.; Wang, H.; Wang, X.; Lu, Q.; Li, H.; Zhang, Y.; Yao, $\mathrm{S}$. $\mathrm{Ti}_{3} \mathrm{C}_{2} / \mathrm{Cu}_{2} \mathrm{O}$ heterostructure based signal-off photoelectrochemical sensor for high sensitivity detection of glucose. Biosens. Bioelectron. 2019, 142, 111535. [CrossRef] [PubMed]

13. Zhang, Y.Z.; Wang, Y.; Jiang, Q.; El-Demellawi, J.K.; Kim, H.; Alshareef, H.N. MXene Printing and Patterned Coating for Device Applications. Adv. Mater. 2020, 32, e1908486. [CrossRef]

14. He, Y.; Ma, L.; Zhou, L.; Liu, G.; Jiang, Y.; Gao, J. Preparation and Application of Bismuth/MXene Nano-Composite as Electrochemical Sensor for Heavy Metal Ions Detection. Nanomaterials 2020, 10, 866. [CrossRef] [PubMed]

15. Naveen, M.H.; Gurudatt, N.G.; Shim, Y.-B. Applications of conducting polymer composites to electrochemical sensors: A review. Appl. Mater. Today 2017, 9, 419-433. [CrossRef]

16. Han, J.; Wang, M.; Hu, Y.; Zhou, C.; Guo, R. Conducting polymer-noble metal nanoparticle hybrids: Synthesis mechanism application. Prog. Polymer Sci. 2017, 70, 52-91. [CrossRef]

17. Naghdi, S.; Rhee, K.; Hui, D.; Park, S. A Review of Conductive Metal Nanomaterials as Conductive, Transparent, and Flexible Coatings, Thin Films, and Conductive Fillers: Different Deposition Methods and Applications. Coatings 2018, 8, 278. [CrossRef]

18. Mao, H.; Liang, J.; Zhang, H.; Pei, Q.; Liu, D.; Wu, S.; Zhang, Y.; Song, X.M. Poly(ionic liquids) functionalized polypyrrole/graphene oxide nanosheets for electrochemical sensor to detect dopamine in the presence of ascorbic acid. Biosens. Bioelectron. 2015, 70, 289-298. [CrossRef]

19. Wang, H.Y.L.; Liu, X.; Zeng, R.; Li, M.; Huang, Y.; Hu, X. Constructing Hierarchical Tectorum-like a-Fe $\mathrm{O}_{3} / \mathrm{PPy} \mathrm{Nanoarrays}$ on Carbon Cloth for Solid-State Asymmetric Supercapacitors. Angew. Chem. Int. Ed. 2016, 56, 1105-1110. [CrossRef]

20. Lee, J.S.; Shin, D.H.; Kim, W.; Jang, J. Highly ordered, polypyrrole-coated $\mathrm{Co}(\mathrm{OH})_{2}$ architectures for high-performance asymmetric supercapacitors. J. Mater. Chem. A 2016, 4, 6603-6609. [CrossRef]

21. Zheng, J.; Zhang, J.; Wang, Z.; Zhong, L.; Sun, Y.; Liang, Z.; Li, Y.; Jiang, L.; Chen, X.; Chi, L. Programmable Negative Differential Resistance Effects Based on Self-Assembled Au@PPy Core-Shell Nanoparticle Arrays. Adv. Mater. 2018, 30, e1802731. [CrossRef]

22. Tian, C.; Du, Y.; Xu, P.; Qiang, R.; Wang, Y.; Ding, D.; Xue, J.; Ma, J.; Zhao, H.; Han, X. Constructing Uniform Core-Shell PPy@PANI Composites with Tunable Shell Thickness toward Enhancement in Microwave Absorption. ACS Appl. Mater. Interfaces 2015, 7, 20090-20099. [CrossRef]

23. Burgoyne, H.A.; Kim, P.; Kolle, M.; Epstein, A.K.; Aizenberg, J. Screening Conditions for Rationally Engineered Electrodeposition of Nanostructures (SCREEN): Electrodeposition and Applications of Polypyrrole Nanofibers using Microfluidic Gradients. Small 2012, 8, 3502-3509. [CrossRef] [PubMed]

24. Jiang, D.; Pang, J.; You, Q.; Liu, T.; Chu, Z.; Jin, W. Simultaneous biosensing of catechol and hydroquinone via a truncated cube-shaped Au/PBA nanocomposite. Biosens. Bioelectron. 2019, 124-125, 260-267. [CrossRef]

25. Liu, T.; Zhao, Q.; Xie, Y.; Jiang, D.; Chu, Z.; Jin, W. In situ fabrication of aloe-like Au-ZnO micro/nanoarrays for ultrasensitive biosensing of catechol. Biosens. Bioelectron. 2020, 156, 112145. [CrossRef]

26. Nam, H.; Kwon, J.E.; Choi, M.-W.; Seo, J.; Shin, S.; Kim, S.; Park, S.Y. Highly Sensitive and Selective Fluorescent Probe for Ascorbic Acid with a Broad Detection Range through Dual-Quenching and Bimodal Action of Nitronyl-Nitroxide. ACS Sens. 2016, 1, 392-398. [CrossRef]

27. Alipour, E.; Majidi, M.R.; Saadatirad, A.; Golabi, S.M.; Alizadeh, A.M. Simultaneous determination of dopamine and uric acid in biological samples on the pretreated pencil graphite electrode. Electrochim. Acta 2013, 91, 36-42. [CrossRef]

28. Zhao, Y.; Gao, Y.; Zhan, D.; Liu, H.; Zhao, Q.; Kou, Y.; Shao, Y.; Li, M.; Zhuang, Q.; Zhu, Z. Selective detection of dopamine in the presence of ascorbic acid and uric acid by a carbon nanotubes-ionic liquid gel modified electrode. Talanta 2005, 66, 51-57. [CrossRef]

29. Yang, L.; Liu, D.; Huang, J.; You, T. Simultaneous determination of dopamine, ascorbic acid and uric acid at electrochemically reduced graphene oxide modified electrode. Sens. Actuators B Chem. 2014, 193, 166-172. [CrossRef]

30. Lin, K.C.; Tsai, T.H.; Chen, S.M. Performing enzyme-free $\mathrm{H}_{2} \mathrm{O}_{2}$ biosensor and simultaneous determination for AA, DA, and UA by MWCNT-PEDOT film. Biosens. Bioelectron. 2010, 26, 608-614. [CrossRef] [PubMed]

31. Zhang, X.; Yu, S.; He, W.; Uyama, H.; Xie, Q.; Zhang, L.; Yang, F. Electrochemical sensor based on carbon-supported NiCoO 2 nanoparticles for selective detection of ascorbic acid. Biosens. Bioelectron. 2014, 55, 446-451. [CrossRef]

32. Mohadesi, A.; Taher, M.A. Electrochemical behavior of Naphthol green B doped in polypyrrole film and its application for electrocatalytic oxidation of ascorbic acid. Sens. Actuators B Chem. 2007, 123, 733-739. [CrossRef]

33. Wei, Z.; Yang, Y.; Xiao, X.; Zhang, W.; Wang, J. Fabrication of conducting polymer/noble metal nanocomposite modified electrodes for glucose, ascorbic acid and tyrosine detection and its application to identify the marked ages of rice wines. Sens. Actuators $B$ Chem. 2018, 255, 895-906. [CrossRef] 
34. Zhang, W.; Liu, L.; Li, Y.; Wang, D.; Ma, H.; Ren, H.; Shi, Y.; Han, Y.; Ye, B.-C. Electrochemical sensing platform based on the biomass-derived microporous carbons for simultaneous determination of ascorbic acid, dopamine, and uric acid. Biosens. Bioelectron. 2018, 121, 96-103. [CrossRef]

35. Abellán-Llobregat, A.; Vidal, L.; Rodríguez-Amaro, R.; Berenguer-Murcia, Á.; Canals, A.; Morallón, E. Au-IDA microelectrodes modified with Au-doped graphene oxide for the simultaneous determination of uric acid and ascorbic acid in urine samples. Electrochim. Acta 2017, 227, 275-284. [CrossRef]

36. Ma, Y.; Zhao, M.; Cai, B.; Wang, W.; Ye, Z.; Huang, J. 3D graphene foams decorated by CuO nanoflowers for ultrasensitive ascorbic acid detection. Biosens. Bioelectron. 2014, 59, 384-388. [CrossRef]

37. Yuan, M.M.; Zou, J.; Huang, Z.N.; Peng, D.M.; Yu, J.G. PtNPs-GNPs-MWCNTs-beta-CD nanocomposite modified glassy carbon electrode for sensitive electrochemical detection of folic acid. Anal. Bioanal. Chem. 2020, 412, 2551-2564. [CrossRef] [PubMed]

38. Gowda, J.I.; Nandibewoor, S.T. Electrochemical behavior of paclitaxel and its determination at glassy carbon electrode. Asian J. Pharm. Sci. 2014, 9, 42-49. [CrossRef]

39. Xu, Y.; Chu, Z.; Shi, L.; Peng, J.; Jin, W. Prussian blue nanocubes decorated three-dimensional silver nanowires network for high-performance electrochemical biosensing. Sens. Actuators B Chem. 2015, 221, 1009-1016. [CrossRef]

40. Du, J.; Yue, R.; Ren, F.; Yao, Z.; Jiang, F.; Yang, P.; Du, Y. Novel graphene flowers modified carbon fibers for simultaneous determination of ascorbic acid, dopamine and uric acid. Biosens. Bioelectron. 2014, 53, 220-224. [CrossRef] [PubMed]

41. Feng, X.Z.; Su, X.R.; Ferranco, A.; Chen, Z.C.; Han, G.C.; Jiang, Z.L.; Kraatz, H.B. Real-Time Electrochemical Detection of Uric Acid, Dopamine and Ascorbic Acid by Heme Directly Modified Carbon Electrode. J. Biomed. Nanotechnol. 2020, 16, 29-39. [CrossRef] [PubMed]

42. He, P.; Wang, W.; Du, L.; Dong, F.; Deng, Y.; Zhang, T. Zeolite A functionalized with copper nanoparticles and graphene oxide for simultaneous electrochemical determination of dopamine and ascorbic acid. Anal. Chim. Acta 2012, 739, 25-30. [CrossRef] [PubMed]

43. Yue, Y.; Hu, G.; Zheng, M.; Guo, Y.; Cao, J.; Shao, S. A mesoporous carbon nanofiber-modified pyrolytic graphite electrode used for the simultaneous determination of dopamine, uric acid, and ascorbic acid. Carbon 2012, 50, 107-114. [CrossRef]

44. Wang, Y.; Xiao, Y. Glassy carbon electrode modified with poly(dibromofluorescein) for the selective determination of dopamine and uric acid in the presence of ascorbic acid. Microchim. Acta 2012, 178, 123-130. [CrossRef] 